\title{
Feasibility evaluation of the 3D-DIC non contact measurement system using small-scaled model test of earth retaining wall
}

\author{
Younghun Ko', Seunghwan Seo ${ }^{1}$, Tailie $\mathrm{Jin}^{2}$ and Moonkyung Chung ${ }^{1 *}$ (D)
}

\author{
${ }^{*}$ Correspondence: \\ mkchung@kict.re.kr \\ ${ }^{1}$ Korea Institute of Civil \\ Engineering and Building \\ Technology, 283 \\ Goyang-daero, Ilsanseo-gu, \\ Goyang-si, Gyeonggi-do \\ 10223, Republic of Korea \\ Full list of author information \\ is available at the end of the \\ article
}

\begin{abstract}
In this study, a small scale experiment of an earth retaining wall was conducted to develop a real-time and full-field noncontact measurement system for earth retaining walls in urban areas. The collapse behavior of the structure was reproduced using a model of an earth retaining wall, and the deformation and displacement of the entire surface of the small scale structure were measured using a 3D image-based digitalimage correlation method employing a stereo camera system. The measured displacement was compared with the actual displacement by using high-precision hexapod equipment in the experiment, and the results confirmed a high level of precision.
\end{abstract}

Keywords: Digital image correlation, Earth retaining wall, Noncontact displacement measurement, Stereo camera

\section{Introduction}

Contact displacement measurements at fixed intervals are limited in estimating the deformation of areas or spaces between positions through interpolation. Therefore, the use of a noncontact displacement-measuring method using camera images is emerging as an alternative or a supplementary measurement tool for measuring displacement.

The existing applications of image-based noncontact measurement at engineering and construction sites mostly involve simple-shaped structures or 2D position measurement systems. The existing image-based 3D displacement measurements can be used only in strictly limited areas. In other words, the current general technology level does not allow its application for high-precision and real-time monitoring at large areas such as an excavation site in urban areas.

Presently, measurements of earth retaining facilities are performed periodically, with each position requiring an analysis of the sequential measurement results. This method is disadvantageous in that it fails to apply ground deformation by considering only the displacement trend at the installation at certain positions. This is a complex measuring method to control the safety of walls through the mutual analyses of displacement using an underground clinometer, the tendency of change of a load gauge, and an axial force meter. Moreover, in many cases, the data about the various changes

(c) The Author(s) 2021. This article is licensed under a Creative Commons Attribution 4.0 International License, which permits use, sharing, adaptation, distribution and reproduction in any medium or format, as long as you give appropriate credit to the original author(s) and the source, provide a link to the Creative Commons licence, and indicate if changes were made. The images or other third party material in this article are included in the article's Creative Commons licence, unless indicated otherwise in a credit line to the material. If material is not included in the article's Creative Commons licence and your intended use is not permitted by statutory regulation or exceeds the permitted use, you will need to obtain permission directly from the copyright holder. To view a copy of this licence, visit http://creativeco mmons.org/licenses/by/4.0/. 
occurring at the rear of the earth-retaining facilities and the deformation of the earth retaining walls are conflicting.

Therefore, technologies that effectively measure the abnormal indications of excavation surfaces and rear ground simultaneously are required. The incidences of the collapsing of earth-retaining facilities in urban areas can be proactively prevented by a quick response to dangerous situations by the development of real-time risk-detecting, full-field, and low-cost measurement systems by using such technologies. In this research, as part of the measure to develop a safety measurement system for earth retaining walls in urban areas, we evaluated the use of a small scale model and displacement operating software of earth retaining wall facilities to verify the measurement precision.

\section{Background}

\section{Stereo camera system}

Figure 1 shows an ideal stereo vision system with two parallel optical axes and two cameras with identical focal lengths. Point $\mathrm{P}$ exists in a 3D space and is projected onto image planes $P_{L}$ and $P_{R}$ of the two cameras; these point are homologous. If $P_{L}$ and $\mathrm{P}_{\mathrm{R}}$ correspond to each other in an image plane, the distance to point $\mathrm{P}$ in a 3D space can be calculated as follows:

$$
\mathrm{Z}=\frac{f \times b}{d_{L}+d_{R}}
$$

where $f$ is the focal distance, which is the distance between the lens centers of the cameras $\left(\mathrm{O}_{\mathrm{L}}, \mathrm{O}_{\mathrm{R}}\right)$ and the image planes, and $b$ is the baseline, which is the distance between the lens centers of the two cameras. Further, $\left(d_{L}+d_{R}\right)$ represents the distance between points $\mathrm{P}_{\mathrm{L}}$ and $\mathrm{P}_{\mathrm{R}}$ of the two image planes, and $\mathrm{Z}$ is a distance to the object or ROI(region of interest). $Z$ is proportional to focal length $f$ and stereo camera baseline $b$ and is reciprocally proportional to $\left(d_{L}+d_{R}\right)$.

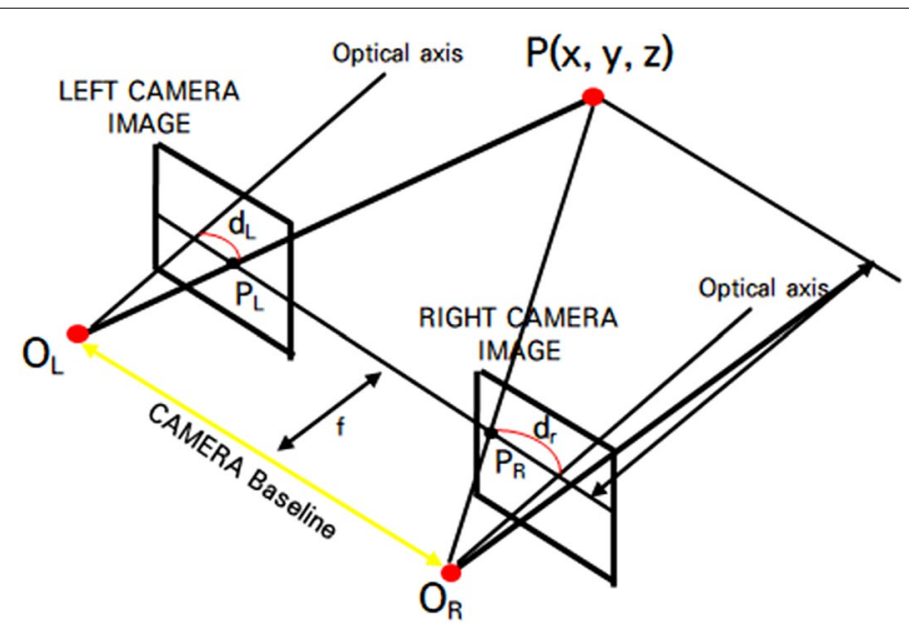

Fig. 1 Schematic of stereo vision 


\section{Digital-image correlation method}

Digital-image correlation (DIC) is a technique used to measure the displacement and deformation of a structure by analyzing images before and after the deformation. The DIC is calculated mainly by using the sum of squared difference (SSD) of equations such as Eq. (2). This technique calculates the structural displacement as a whole by dividing random patterns distributed in images into facets of small units. It also calculates the distance of each facet movement in the deformation images $[9,10]$.

$$
C_{S S D}=\sum \sum\left[g\left(x^{\prime}{ }_{i}, y_{i}^{\prime}\right)-f\left(x_{i}, y_{j}\right)\right]^{2}
$$

where $C_{S S D}$ is the correlation coefficient, $g$ is the gray-scale value for the deformed images, $f$ is the gray-scale value for the reference images, $x^{\prime}{ }_{i}$ and $y_{i}^{\prime}$ are pixel coordinates for the deformed images, and $x_{i}$ and $y_{j}$ are pixel coordinate values for the reference images. The DIC method was modified [1, 2, 4, 5, 12] to improve the acquired image quality, algorithms, and image correlation processing to produce reliable and accurate strain mapping results. The accuracy of the DIC method can be less than 0.01 pixels [11]. The DIC method is becoming more prominent in whole-field surface strain mapping applications that analyze various materials, including rock [7], Weng et al. [13]), granular material [8], and concrete [3]. In contrast to previous laboratory studies, this study adopted the 3D DIC method to measure the deformation of earth retaining walls. To obtain appropriate digital images for DIC analysis, the preparation procedures in the small scale model were developed first. The acquired digital images were then analyzed to identify the deformation patterns in the small scale model of an earth retaining wall.

\section{Methods}

\section{Stereo system for a large-scale model}

The 3D DIC system based on the stereo vision theory is considered as one aspect in the development of a 3D real-time image data-based displacement measurement system, which is optimized for the measurement of urban-area excavation sites, with verified system precision in a full-scale experiment.

A high-precision level was set as the target (out-of-plane displacement precision of $0.5 \mathrm{~mm}$ ) at the region of interest (ROI: $30 \mathrm{~m} \times 20 \mathrm{~m}$ ) and the displacement measurement error of the large-area 3D-DIC was assessed. Then, to confirm the optimized installation positions of the stereo cameras, the precision of displacement measurements on the $x-, y-$, and $z$-axes were calculated, as shown in Fig. 2, while varying factors such as the camera baselines, camera optical angles, and distance between the cameras and subjects.

Theoretically, within the field of view $(30 \mathrm{~m} \times 20 \mathrm{~m})$, the plane measurement error was $\pm 0.15 \mathrm{~mm}$; however, the experimentally measured plane error was $\pm 0.25 \mathrm{~mm}$. Moreover, the theoretical error of plane displacement was $\pm 0.45 \mathrm{~mm}$, whereas the measurement result was $\pm 0.8 \mathrm{~mm}$. Therefore, the measurement results were observed to be approximately two times the magnitude of the theoretical results. These measurement errors were applicable when the distance between the cameras was 9-13 $\mathrm{m}$, the camera angle varied between $20^{\circ}$ and $25^{\circ}$, and the distance to the subject was $32 \mathrm{~m}$ [6]. 


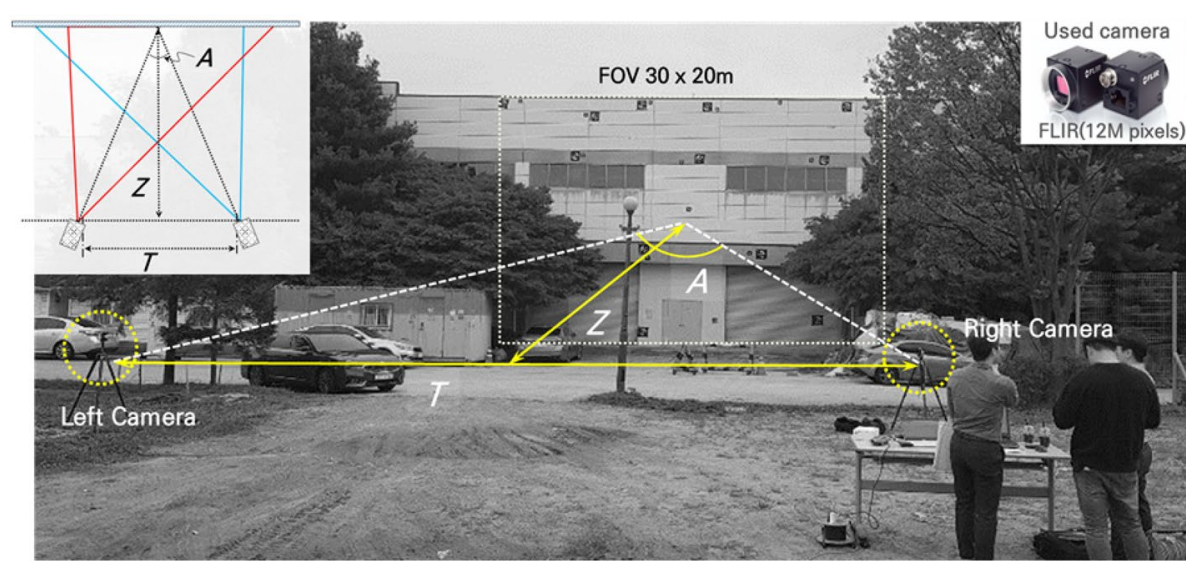

Fig. 2 Large-Scale 3D-DIC system

\section{Small scale model (earth retaining wall and building)}

Figure 3 shows the small scale model of an earth retaining wall facility. The length and height of the wall and building were $300 \mathrm{~mm}$; the small scale model was produced at a $1 / 40$ th scale. For the front side of the model, an elastic material was printed using a 3D printer. The printing material used was an elastic rubber material that differs from the common 3D printer material and possessed a high level of shape reproduction.

Seven actuators were installed on the retaining wall surface. As one or several actuators may be synchronously controlled and moved at a predetermined velocity and distance, various types of collapse shapes could be reproduced. For the displacements of the small scale building, axial displacements of $X, Y$, and $Z$ along with $U, V$, and $W$ angles were controlled using PI hexapods (H-820). The hexapods and actuators can be operated simultaneously, and this combination can mimic the inclination, subsidence, and collapsing characteristics of buildings and earth retaining walls.

Each of the seven actuators was controlled in the forward and back directions with a computer and was connected to the rubber-like elastic outer wall to create a deformed appearance.

The hexapod could move precisely in the $X, Y, Z, U, V$, and $W$ directions, and the ground subsidence and toppling of a building could be simulated by placing a building on top of the hexapod. When these two devices were used together, it was possible to simulate the collapse of the earth retaining wall and the process of subsidence or toppling of the building.

\section{Testing methods}

To simultaneously measure the displacements of the small scale models of the earthretaining walls and buildings, the area of the 3D DIC system was calibrated to $740 \mathrm{~mm} \times 600 \mathrm{~mm}$, with distances of $260 \mathrm{~mm}$ between the cameras and $740 \mathrm{~mm}$ between the cameras and subjects; the optical angle was $25^{\circ}$.

The theoretical plane error of the 3D DIC measurement system was \pm 0.02 pixels and the out-of-plane error was 2-4 times the plane error. Such errors occur when calculating 

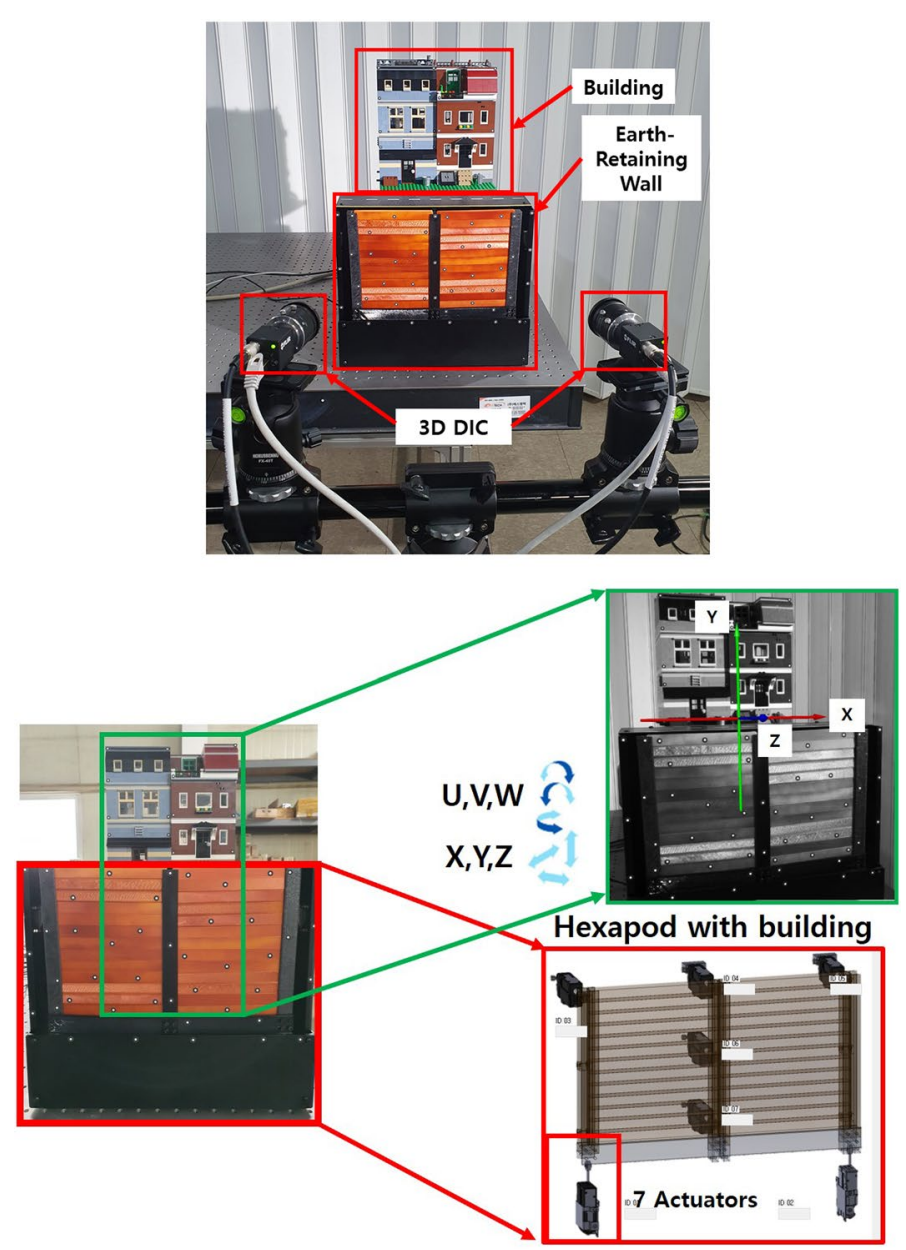

Earth Retaining Wall

Fig. 3 Scale model of building and earth-retaining wall

a value numerically. The number of errors increases with respect to cameras, lenses, the calibration state of cameras, and measurement circumstances. The experiments showed a measurement error of 0.02 pixels, indicating that the measurement error was directly proportional to the measurement area; this finding is a significant contribution of this study. When the area was calibrated to $740 \mathrm{~mm} \times 600 \mathrm{~mm}$, the theoretical plane error was $3.7 \mu \mathrm{m}$ and the out-of-plane error was $2-4$ times this value.

In this experiment, we used high-precision cameras and lenses obtained from FLIR Co., Ltd., which previously configured large-area 3D DIC systems; this minimized the measurement errors based on the reduction of the measurement area.

The most important aspect of stereo-camera-based 3D measurements is 3D calibration; common stereo calibration can be divided into two types: calibration of camera distortion and the acquisition of position data of the cameras. The larger the measurement area, the greater is the distortion calibration. The calibration of the camera distortion generally requires a point matrix and checkerboard. To calibrate the distortions of a full range of cameras, a calibration object with the same size as the measurement range should be used. 

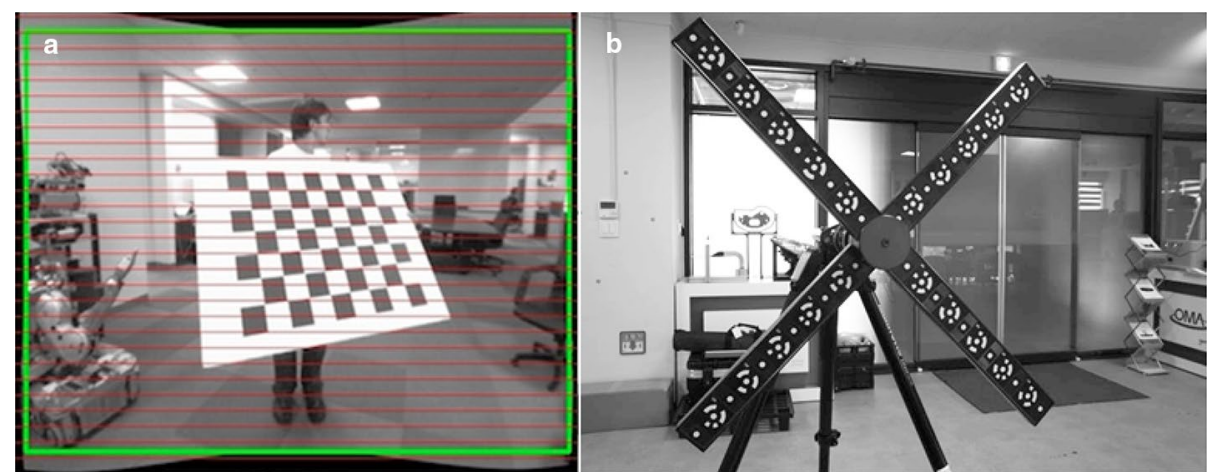

Fig. 4 a Process of 3D calibration using checkerboard on an OPEN CV. $\mathbf{b}$ Cruciform 3D calibration object of corporate $G$

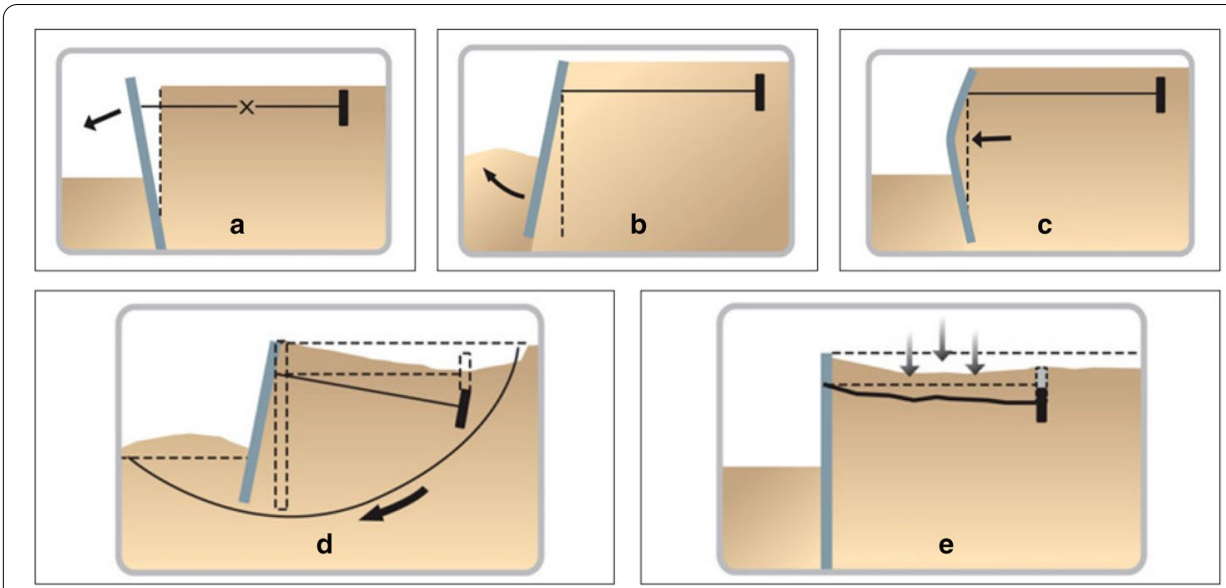

Fig. 5 Collapse behaviors of earth-retaining wall. a The wall collapses owing to the destruction of an anchor (or a brace). $\mathbf{b}$ The collapse occurs when the excavation-side ground is weak or the lower part of the ground is pushed out because of the lack of the embedding length of the earth-retaining wall. c The wall collapses when members of an earth-retaining wall cannot bear the bending moment generated on the wall. $\mathbf{d}$ The collapse occurs when the whole structure of the earth-retaining wall is totally destroyed owing to slope movement. e This collapse accompanies a collapse due to the loss of the bearing capacity of an anchor (or brace) installed at the rear owing to the partial subsidence of the wall or rear ground

However, as the development of a large-sized calibration object is difficult; calibration is performed using a small calibration object. As such, sufficient calibration data on the edges will not be obtained. To overcome this shortcoming, a cruciform calibration object with a size of $700 \mathrm{~mm}$ was used as shown in Fig. 4, and the camera distortion was calibrated by capturing photographs from various angles.

\section{Displacement behavior of the small scale model}

Figure 5 shows the common collapse types of the earth retaining walls. Possible modes of failure for earth retaining walls are illustrated in Fig. 5. Earth retaining walls usually fail by rigid-body mechanisms such as failure by overturning (a), failure of the wall due to insufficient passive capacity (b), gross instability failure (c), rotational failure of groundmass (d), and failure due to insufficient axial capacity(e). 


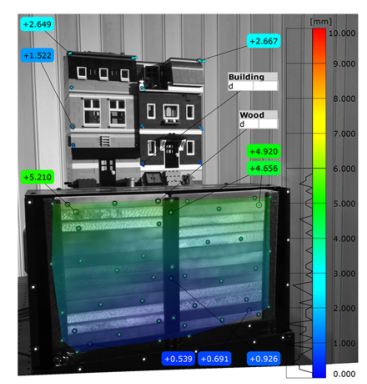

a

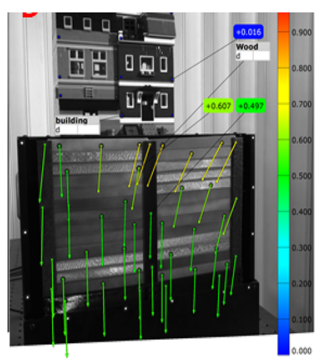

d

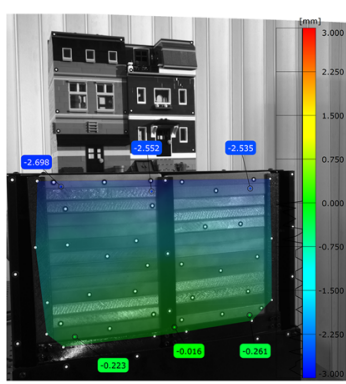

b

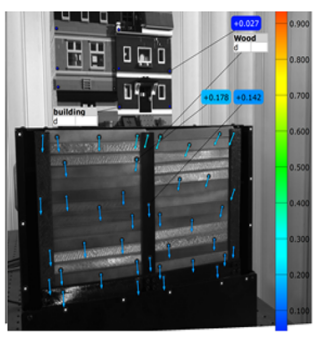

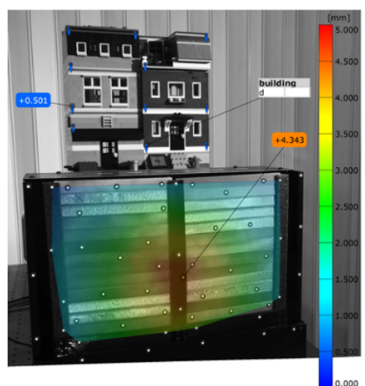

C

Fig. 6 Common collapse types of the earth-retaining walls and 3D-DIC results

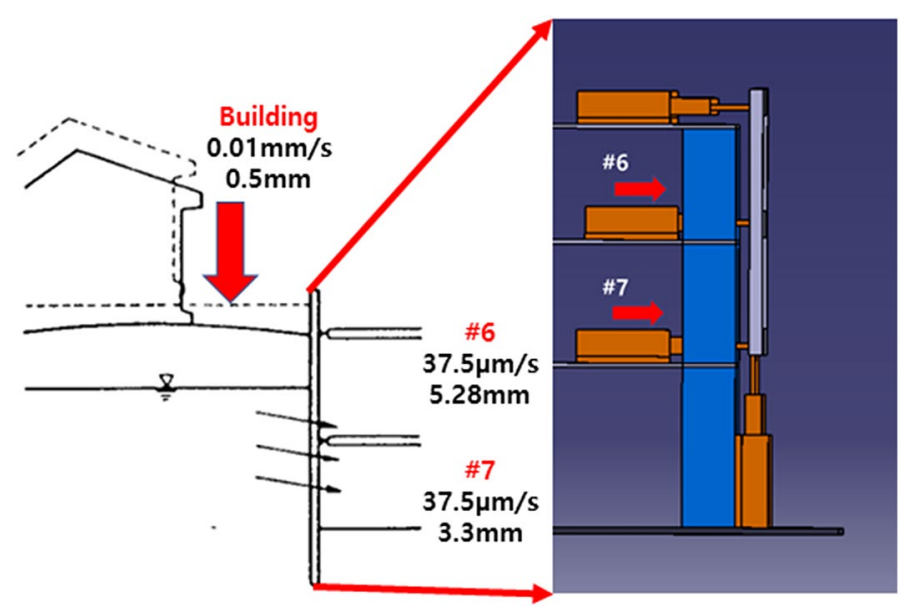

Fig. 7 Settings of the movement of the building and earth-retaining wall

We performed experiments for each collapse type by encoding the movement using software to operate the displacement of the small scale of the earth-retaining wall as shown in Fig. 6.

\section{Results and discussion}

The experiment was conducted for two main reasons. First, the process of collapse of an earth retaining wall was measured using the 3D DIC measurement system. We considered different collapse modes by using the collapse type shown in Fig. 5 (c), which resulted in total destruction. This was confirmed as shown in Fig. 7 through the small scale model, in which the hexapod moved downward(-y direction) by up 
to $0.5 \mathrm{~mm}$ at a velocity of $0.01 \mathrm{~mm} / \mathrm{s}$, and axes 6 and 7 in the earth-retaining facilities moved forward up(z direction) to 5.28 and $3.3 \mathrm{~mm}$, respectively, at velocities of $37.5 \mu \mathrm{m} / \mathrm{s}$ each.

Second, the measurement precision and accuracy of the 3D-DIC system were checked. The small scale building was connected to the hexapod device with very high precision such that the displacement of the building directly reflected the movement of the hexapod. By comparing the displacement of the building with the displacement results calculated using the 3D DIC system, the actual precision can be assessed.

In Fig. 8, point (a) represents the reference position. In point (b), the building subsides up to $0.2 \mathrm{~mm}$, while the earth retaining facility moves forward (z direction) to $1.5 \mathrm{~mm}$. In point (c), the subsidence of the building stops, and the earth retaining facility experiences continuous collapse conditions. In point (d), all movement stops, and the building has subsided up to $0.496 \mathrm{~mm}$ and displaced up to $5.11 \mathrm{~mm}$ of the earth-retaining wall.

Figure 9 illustrates the image results measured at Fig. 8 point (a), (b), (c), and (d), and the displacement results of the earth retaining facilities show the full range of displacements and deformations through interpolation. Moreover, effects similar to the installation of numerous measuring sensors could be obtained.

Figure 10 shows the 3D deformation of the earth retaining wall by the 3D-DIC system measured point (a), (b), (c), (d) in Fig. 8 respectively. the deformation was expressed by enlarging the total deformation 30 times. Two actuators in the middle part of the small scale model were controlled to move $5.28 \mathrm{~mm}$ in the $+\mathrm{Z}$ direction. Although 3D-DIC result was $5.11 \mathrm{~mm}$ measured due to actuator movement accuracy error. It was considered to be due to the material resistance of the small scale models of the earth-retaining walls.

The small scale model in this research has a scale of 1:40; therefore, the maximum displacement of $5.11 \mathrm{~mm}$ generated in the small scale model can be regarded as a deformation of approximately $200 \mathrm{~mm}$ in full-scale structures.

The average velocity measured using 3D DIC was $0.0091 \mathrm{~mm} / \mathrm{s}$, and the difference between this velocity and the velocity of the hexapod movement is $0.001 \mathrm{~mm} / \mathrm{s}$. Figure 8 shows that at point $(\mathrm{d})$, the displacement of the building measured using the 3D-DIC system is $0.496 \mathrm{~mm}$, which shows a difference of $0.004 \mathrm{~mm}$ when compared with the

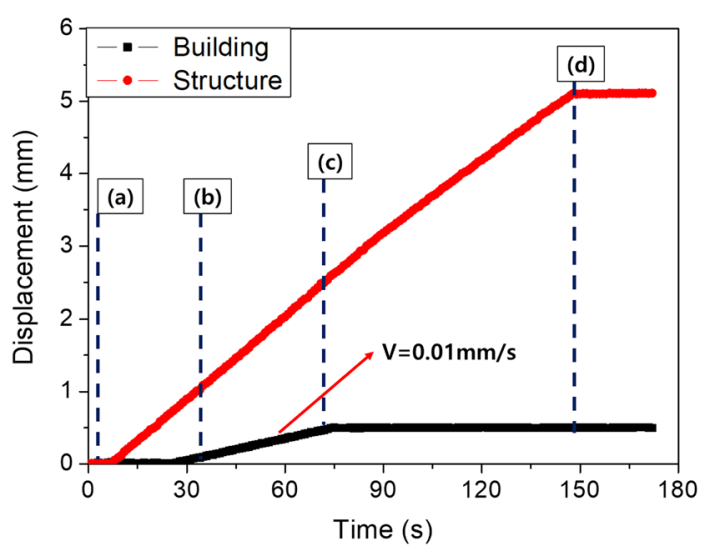

Fig. 8 Displacement values of sections A, B, C, and D with structural deformation 


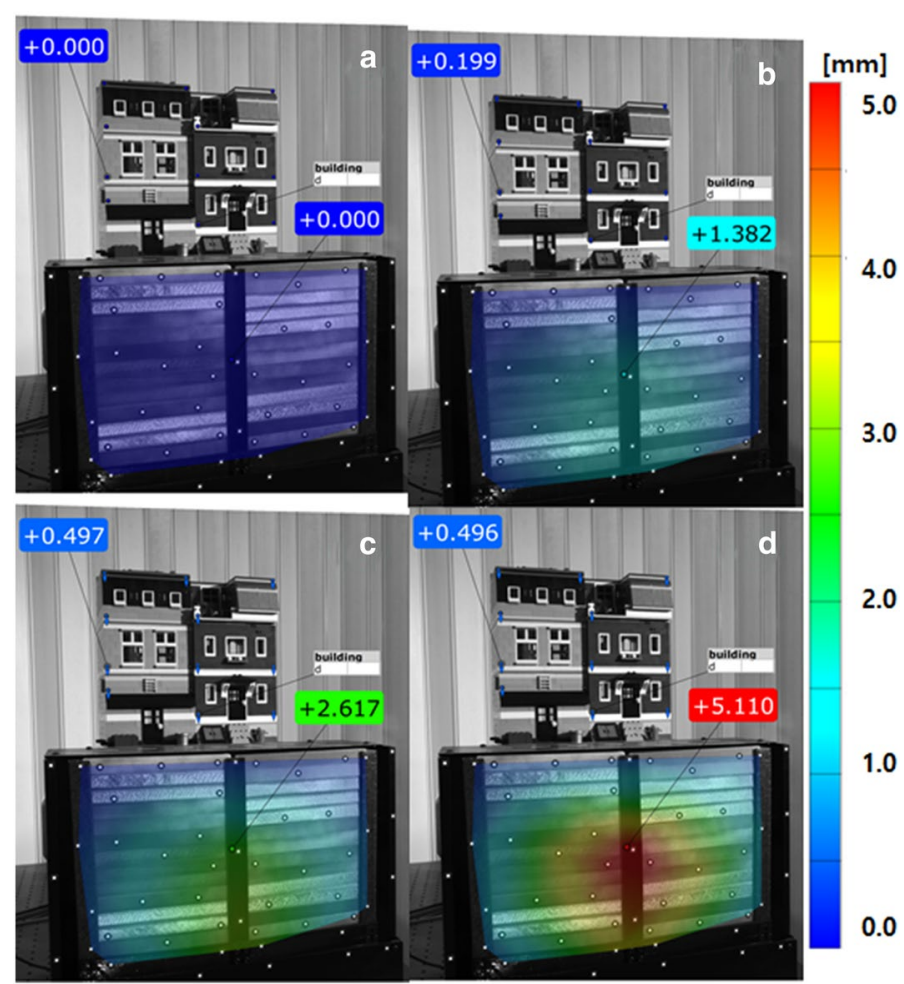

Fig. 9 Full-field displacement results

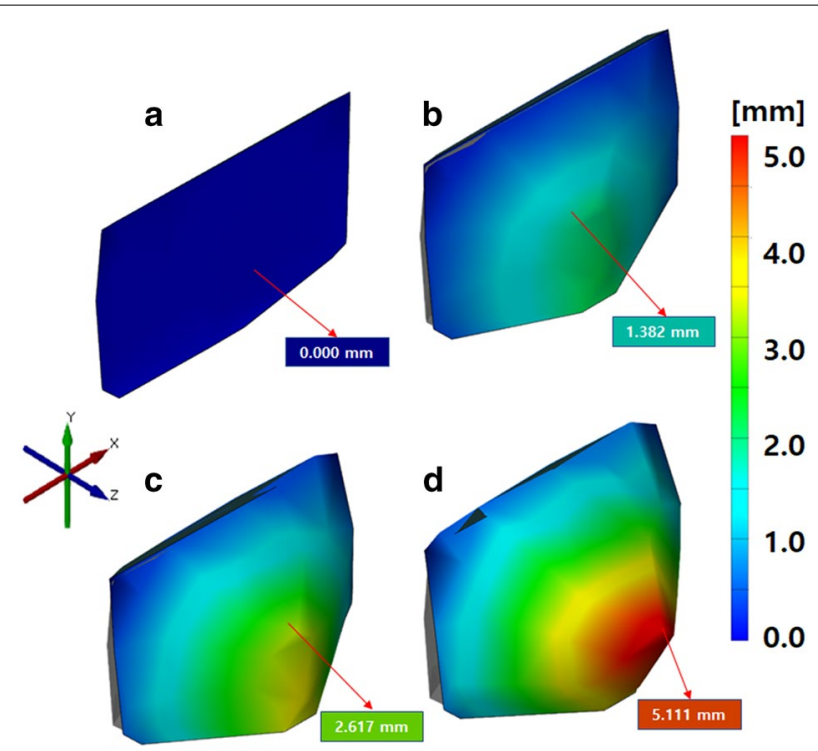

Fig. $103 \mathrm{D}$ deformation of the earth retaining wall by the 3D-DIC system

distance of $0.5 \mathrm{~mm}$ of the hexapod movement. Considering the measurement precision of the 3D-DIC system, its measurement reliability is very high. Also, the measurement accuracy of only $0.8 \%$ error occurred. 


\section{Conclusions}

In this research, as part of the measure to develop a safety measurement system for earth retaining walls in urban areas, we investigated the use of a small scale model and displacement operating software of earth retaining wall facilities to verify the measurement precision of a noncontact 3D image-based displacement measurement system at a target measurement area. In addition, we verified the applicability of a stereo camera system for the measurement. The following conclusions can be drawn from this study.

(1) The experimental results of the stereo camera system with a broad baseline distance configured for a full-scale experiment by implementing the system in an indoor environment showed the camera's baseline distance to be linearly related to the distance from the object. The results confirmed the possibility of an alternative role for the full-scale experiment of a small scale model of an earth retaining facility using an image-based displacement-measurement system.

(2) By using a small scale model of earth-retaining wall, we reproduced the excessive deformation behavior of each collapse type by artificially controlling the aspects of earth retaining walls, the rear ground, and neighboring buildings. The 3D DIC system showed the scale model to depict collapse behavior with various deformation ranges and high superposition (position overlapping). The comparison of the measurement results of the moving velocities of the small scale building and hexapods showed an error of approximately $0.001-0.003 \mathrm{~mm} / \mathrm{s}$ and the error considering the moving distance of approximately $0.001-0.005 \mathrm{~mm} / \mathrm{s}$. We confirmed the feasibility of target precision on develpoed 3D DIC system.

In the future, we will actively utilize small scale models to configure algorithms for 3D image identification of earth retaining facilities and their collapse behaviors, and determine an object-recognition function for collapse risks and excessive displacement situations.

Acknowledgments

This research was supported by a grant (code: 21SCIP-C151438-03) from the Construction Technologies Program funded by the Ministry of Land, Infrastructure and Transport of the Korean government.

Author details

${ }^{1}$ Korea Institute of Civil Engineering and Building Technology, 283 Goyang-daero, Ilsanseo-gu, Goyang-si, Gyeonggi-do 10223, Republic of Korea. ${ }^{2}$ Omagom Limited Company, 66, Munji-Ro, 299Beong-Gil, Yuseong-Gu, Dajeon, Republic of Korea.

Received: 23 September 2020 Accepted: 15 January 2021

Published online: 02 May 2021

References

1. Brillaud F, Lagattu F (2006) Digital correlation of grainy shadow images for surface profile measurement. Optik 117:411-417. https://doi.org/10.1016/j.ijleo.2005.10.012

2. Bruck HA, McNeill SR, Sutton MA, Peters WH (1989) Digital image correlation using Newton-Raphson method of partial differential correction. Exp Mech 29(3):261-267

3. Choi SP (1997) Measurement of deformations on concrete subjected to compression using image correlation. Exp Mech 37:307-313. https://doi.org/10.1007/BF02317423

4. Chen DJ, Chiang FP, Tan YS, Don HS (1993) Digital speckle displacement using a complex spectrum method. Appl Opt 32:1839-1849. https://doi.org/10.1364/AO.32.001839

5. James MR, Morris WL (1990) A high accuracy automated strain-field mapper. Exp Mech 30:60-67. https://doi.org/10. 1007/BF02322704

6. Ko YH, Seo SH, Lim HS, Jin TL, Chung MK (2020) Design and verification of 3D digital image correlation systems for measurement of large object displacement using stereo camera. Explosives Blasting 38:1-12 
7. Louis L, Wong TF, Baud P (2007) Imaging strain localization by X-ray radiography and digital image correlation: deformation bands in Rothbach sandstone. J Struct Geol 29:129-140. https://doi.org/10.1016/j.jsg.2006.07.015

8. Rechenmacher AL, Finno RJ (2004) Digital image correlation to evaluate shear banding in dilative sands. Geotech Test J 27:13-22. https://doi.org/10.1520/GTJ10864

9. Sutton MA, Wolters WJ, Peters WH, Ranson WF, McNeil SR (1983) Determination of Displacements Using an Improved Digital Correlation Method. Image Vis Comput 1(3):133-139

10. Sutton MA, Mingqi C, Peters W, Chao Y, McNeill S (1986) Application of an optimized digital correlation method to planar deformation analysis. Image Vis Comput 4(3):143-150

11. Sutton MA, Turner JL, Bruck HA, Chae TA (1991) Full-field representation of discretely sampled surface deformation for displacement and strain analysis. Exp Mech 31(2):168-177

12. Vendroux G, Knauss WG (1998) Submicro deformation field measurements, part 2. improved digital image correlation. Exp Mech 38:86-91

13. Weng MC, Tung SH (2009) Microscopic characteristics of problematic Tertiary sandstone as revealed by grain-wide local deformation. Int J Rock Mech Min Sci 46:1243-1251. https://doi.org/10.1016/j.jirmms.2009.04.005

\section{Publisher's Note}

Springer Nature remains neutral with regard to jurisdictional claims in published maps and institutional affiliations.

\section{Submit your manuscript to a SpringerOpen ${ }^{\odot}$ journal and benefit from:}

- Convenient online submission

Rigorous peer review

Open access: articles freely available online

- High visibility within the field

- Retaining the copyright to your article

Submit your next manuscript at $\boldsymbol{\Delta}$ springeropen.com 